\section{Postoperative intraocular pressure spikes: the need to treat}

P Tranos, G Bhar and B Little

\begin{abstract}
Raised intraocular pressure (IOP) still holds pride of place as the principal risk factor for developing glaucoma. The detrimental effects of chronically elevated IOP on the optic disc are well known. However, the clinical significance of acutely raised IOP is less certain.
\end{abstract}

Transient acute elevations of intraocular pressure (IOP spikes) occur following many surgical and laser procedures. Cataract extraction, glaucoma surgery, pars plana vitrectomy with fluid air exchange, Nd-YAG capsulotomy, or peripheral iridotomy, and laser trabeculoplasty all have been reported to be associated with variable IOP spikes in the early postoperative period. ${ }^{1-6}$

There is considerable diversity of opinion concerning how these IOP spikes should best be managed. We have reviewed the nature and quality of the available experimental and clinical data relating to IOP spikes and we offer some broad, general guidelines for their clinical management.

Eye (2004) 18, 673-679. doi:10.1038/sj.eye.6701319

Published online 27 February 2004

Keywords: intraocular pressure spikes; autoregulation; glaucoma; tissue integrity

\section{Experimental data}

\section{Key concepts}

Assessment of the experimental evidence as to whether or not IOP spikes cause damage to ocular tissues highlights the crucial role of blood flow autoregulation and intrinsic tissue integrity. Effective autoregulation combined with tissue robustness may together minimize the potential damage from a transient rise in IOP. We therefore looked at experimental data that addressed the following issues:

(1) How much autoregulation is possible to counteract the risk from pressure-induced ischaemia and in what tissue?

(2) How extensively can cellular integrity and function be maintained in the acutely raised IOP state?

Autoregulation; the effect of IOP on local blood flow

Autoregulation in this context refers to the ability of the ocular circulation to maintain constant blood flow despite changes in the perfusion pressure. Historically, autoregulation of cerebral flow was initially suggested by $\mathrm{Fog}^{7}$ in 1934 , but Porsaa $^{8}$ was probably the first to report evidence for autoregulation of blood flow within the retina. With IOP elevation the perfusion pressure decreases, but the capacity of the retina to autoregulate its blood flow enables it to maintain the constancy of the local microenvironment and protects the tissues from fluctuations in perfusion pressure. Therefore any experimental data demonstrating effective autoregulation in the eye would contribute strongly to the argument that IOP spikes contribute little if any effect on ocular blood flow.

\section{Experimental techniques}

A variety of animal experiments have been conducted to investigate the effect of acute IOP changes on both ocular haemodynamics and the sensitivity of ocular tissues to pressure change. There are still uncertainties, and each method of assessment has its limitations. The extrapolation of the animal model to humans also remains controversial. More recently, noninvasive techniques have been developed to obtain in vivo data from human subjects.
Royal Free Hospital Pond Street London, UK

Correspondence: P Tranos Royal Free Hospital Pond Street London NW3 2QG, UK Tel: + 442072885572 Fax: +442072883924

E-mail: ptranos@ hotmail.com

Published online: 27 February 2004 
Various investigation methods have been employed including cine angiography, ${ }^{9}$ labeled microsphere studies ${ }^{10-12}$ and dye testing, ${ }^{13}$ which attempt to quantify blood flow. Other techniques enable continuous monitoring using non-invasive laser Doppler flowmetry ${ }^{14}$ and colour Doppler imaging. ${ }^{15}$ Direct histological and morphological analyses have also been used. More recently, immunohistochemical labelling has been used for a quantitative analysis of neurotrophic agents in the optic nerve head $(\mathrm{ONH})$ after pressure rises, ${ }^{16}$ and identification of gene upregulation in the trabecular meshwork. ${ }^{17}$ Electrophysiological investigations have concentrated particularly on functional cellular activity of retinal ganglion cells, ${ }^{18,19}$ which demonstrate that in transient IOP elevations the electrical function of the ganglion cell depends upon the perfusion pressure (mean blood pressure-IOP), and not the absolute height of the IOP. ${ }^{18}$

\section{Specific animal experimental models}

Alm and Bill ${ }^{10,20}$ reported two techniques used to investigate retinal oxygen supply and blood flow in cats. The first investigated changes in $\mathrm{PVrO}_{2}\left(\mathrm{PO}_{2}\right.$ in the vitreous body close to the retina) as a consequence of changes in IOP, arterial $\mathrm{BP}$, arterial $\mathrm{PO}_{2}$, and arterial $\mathrm{PCO}_{2}$. As perfusion pressure was lowered from a normal value of $144 \mathrm{cmH}_{2} \mathrm{O}$ (by raising IOP or lowering the mean arterial pressure), no significant reduction in $\mathrm{PVrO}_{2}$ was seen until values reached $50-100 \mathrm{cmH}_{2} \mathrm{O}$. A moderate reduction in perfusion pressure therefore caused no change in $\mathrm{PVrO}_{2}$. Quantitative measurements at high IOP values (unspecified) indicated that there might even be a rise in retinal blood flow. ${ }^{20}$

The second experiment ${ }^{10}$ aimed to determine quantitatively blood flow through the retina and parts of the uvea. With the aid of radioactively labelled microspheres, researchers analysed the effects on the blood flow values of altering IOP and arterial $\mathrm{CO}_{2}$. IOP was elevated within the assumed autoregulatory range in one eye and sustained at this level for at least $20 \mathrm{~min}$ before the injection of the microspheres. The fellow eye recorded a spontaneous IOP. Results revealed that in over $90 \%$ of cases eyes with increased IOP in fact had higher blood flow value compared to their controls. This was recorded both as an instantaneous ability and after a 20-min pause at the higher IOP, whereupon blood flow in this setting was even higher than in control eyes.

The above two experiments confirm a retinal autoregulatory capability at IOP pressures that moderately reduce the perfusion pressure and they also provide ample support that autoregulation protects continuously against transient rises of IOP.
Although early studies suggested that autoregulation is absent in the optic nerve head, ${ }^{11,21,22}$ later reports using animal models showed otherwise. ${ }^{12,23-26}$

Geijer and Bill ${ }^{12}$ performed experiments utilizing microsphere methods in primates. They raised the IOP and rapidly or 5-7 $\mathrm{h}$ later assessed the flow in the retina and different parts of the optic nerve head. In addition, they made blood flow determinations following a severe transient IOP spike above the systolic BP (no flow state) for 20-30 min. Retinal autoregulation was present, resulting in little reduction in flow $(1.1 \pm 0.1 \mathrm{mg} / \mathrm{min} /$ $\mathrm{mm}^{3}$ ) until perfusion pressures were dropped beyond $40 \mathrm{cmH}_{2} \mathrm{O}$. When IOP was above the systolic BP, then predictably no flow was seen.

A similar response to raised IOP was observed in the prelaminar optic nerve head blood flow. In the laminar region, there was a tendency for the anterior region to receive less blood than the posterior. The retrolaminar region showed a reactive hyperaemia, either due to vasodilation from metabolite diffusion backwards, or from mechanical redistribution of blood backwards. Finally, blood flow in further retrolaminar regions seemed to be unaffected by the IOP.

These experimental results showed overall that blood flow in the optic nerve head was no more IOP sensitive than the retinal flow, and that both could maintain effective autoregulation for $5-7 \mathrm{~h}$ at perfusion pressures above $50 \mathrm{mmHg}$. Further studies by Weinstein et al supported these reports. ${ }^{25,26}$

\section{Human experimental models}

Application of these results to the human eye requires careful extrapolation. The perfusion pressure in the human eye is normally about $75 \mathrm{cmH}_{2} \mathrm{O}$ in the erect posture. In the monkey, blood flow becomes IOP sensitive at a perfusion pressure of around $40 \mathrm{cmH}_{2} \mathrm{O}$. If the threshold in humans is similar, there is up to a $35 \mathrm{cmH}_{2} \mathrm{O}$ margin before further decreases in perfusion pressure (from increases in IOP) will result in a marked reduction in blood flow through the retina and optic nerve head. In contrast, eyes with vessels that are significantly sclerotic, or prone to anterior ischaemic optic neuropathy (AION), are thought likely to have exhausted their autoregulatory mechanisms even at normal pressures. ${ }^{12}$

Autoregulation in the retinal vasculature of humans was confirmed using laser Doppler velocimetry techniques. ${ }^{27,28}$ Although these studies were performed on eyes with established glaucoma, the preceding animal data suggest that transient IOP elevations probably provoke a similar reaction.

Evidence of a regulatory response was first appreciated in the human optic nerve head in 1982 by 
means of a laser Doppler velocimeter. ${ }^{29}$ Most investigators have concluded that there is effective autoregulation of blood flow in the healthy optic nerve head of the human eye. ${ }^{30-32}$ However, Joos et al are alone in concluding that the human optic nerve head cannot autoregulate, ${ }^{15}$ but they studied exclusively the blood flow velocities in the short posterior ciliary artery in response to large acute IOP rises.

More recently, Pillunat et l $^{14}$ using laser Doppler flowmetry studied optic nerve head circulation in response to increased IOP. They concluded that there is evidence of efficient regulation of blood flow in the human optic nerve head, but in certain individuals it may be locally absent. Finally, angiographic evidence suggests that in humans the peripapillary choroidal flow is maintained with IOP as high as $80 \mathrm{mmHg}{ }^{30}$

\section{Effect of IOP spikes on tissue Integrity}

The maintenance of cellular integrity and function in the presence of a transient IOP elevation remains the central issue whatever the responsiveness of the nutrient arteries. Extraneuronal and particularly neuronal tissue can be affected by a rise in IOP. The severity of damage has been shown to correlate best with the relative perfusion pressure, and not the absolute level of the IOP. $^{33}$

A study on tissue changes attributable to IOP spikes was reported in 1975 utilizing eight anaesthetized owl monkeys. ${ }^{31}$ They were subjected to very high constant IOP elevation in one eye for $8 \mathrm{~h}$. The resultant perfusion pressures were between +15 and $-15 \mathrm{mmHg}$. Following the sustained rise, the IOP was returned to normal, and 3 or 4 weeks later animals were killed. Results showed that lower perfusion pressures were accompanied by more extensive ocular damage with variable destruction of outer retinal layers, significant ganglion and nerve fibre layer atrophy, and optic disc atrophy. In addition, there was early involvement of the anterior uvea, which may suggest that the anterior ciliary circulation (long posterior ciliary supply, anterior ciliary supply) has a lower threshold for damage than the retina.

However, the IOP levels induced were considerably higher than those generally seen in the postoperative situations. At these high IOP levels, the data imply that the ciliary processes are compromised early, resulting in reduced aqueous production and creating an upper limit to the IOP elevation before injury to the retina.

Postoperative IOP spikes may therefore have a maximum self-limiting value beyond which aqueous production ceases, and this self-limited maximum IOP may be well below the level at which damage occurs to the outer retina and optic disc.
Other animal studies assessed optic disc vascular permeability using fluorescein angiography following transient IOP elevations. These showed clearly that a blood-brain barrier breakdown occurred together with disruption of axonal transport in the optic nerve head, but these changes were reversible in all instances. ${ }^{32}$

Experiments in which complete ischaemia of the optic nerve head and retina was induced, demonstrated that tissue changes were irreversible after a 4 -h insult, but partly reversible between 1 and $2 \mathrm{~h}$ of insult. ${ }^{33}$ At perfusion pressures of $25-30 \mathrm{mmHg}$ (which may be comparable to a postoperative episode of significantly reduced perfusion pressure), no permanent nerve injury was identified even after $4 \mathrm{~h}$. Authors suggest that this demonstrates significant axonal resilience with regard to postoperative IOP elevations. The study showed that some axons can survive even total ischaemia for $2 \mathrm{~h}$. The authors emphasize the greater axonal resistance of the axons compared to the retinal ganglion cell bodies.

Cell death is considered to occur by apoptosis or programmed cell death. In a more recent study ${ }^{34}$ on rats, investigators elevated IOP to $110 \mathrm{mmHg}$ and sustained this for $1-2 \mathrm{~h}$, before studying retinas at $2-48 \mathrm{~h}$ intervals after the elevation. Analysing morphology, patterns of DNA fragmentation, and TdT-mediated biotin-dUTP nick end labelling (TUNEL), they also concluded that transiently elevated IOP of this severity did cause apoptosis of retinal ganglion cells and neurons of the inner nuclear layers, in a delayed manner. Additionally, they found that photoreceptor cells were resistant to the induced apoptosis.

A current hypothesis on the mechanism of programmed cell death is that pressure-induced axonal transport obstruction of the optic nerve head inhibits retrograde delivery of neurotrophic substances by retinal ganglion cells. This then triggers the programmed cell death. Many neurotrophins have been identified, and immunohistochemical techniques have been used to detect altered neurotrophin distribution. ${ }^{16}$ However, these studies showed that extensive disruption to cellular integrity and function required very high levels of IOP that are unlikely to be reached during most postoperative IOP spikes.

\section{Clinical data}

\section{IOP spikes following cataract surgery}

The original identification of postoperative IOP spikes following cataract extraction was reported in the 1950s and $1960 \mathrm{~s}^{35-40}$ with Gormaz ${ }^{38}$ being the first to report ocular hypertension 1 day after cataract surgery. In 1968, $\mathrm{Rich}^{40}$ suggested that an early postoperative rise followed all cases of cataract surgery in which the closure 
of the incision was watertight. He reported postoperative pressures following uncomplicated intracapsular cataract extraction of a mean maximum value of $39.3 \mathrm{mmHg}$ at approximately $7 \mathrm{~h}$. In most cases the pressure failed to decrease to preoperative levels within the observation period of $26 \mathrm{~h}$. These figures are no longer relevant with the abandonment of intracapsular surgery in the developed world.

Subsequent clinical studies of IOP spikes were based largely upon cataract surgery and underlined the transient nature of postoperative ocular hypertension. Smith and Anderson ${ }^{41}$ reviewed 630 cases of cataract extraction with lens implants and revealed many instances of transient IOP elevation although the exact incidence was uncertain. They, nevertheless, identified this phenomenon as benign, and showed that the IOP returned to a normal level in $95.7 \%$ of a nonglaucomatous group of patients $(n=606)$, with or without treatment. The residual $4.3 \%$ incidence of postoperative secondary glaucoma was higher than that found in other series. The authors attributed this to the fact that a number of patients were classified as having permanent 'postoperative glaucoma' on the basis of a single measurement of elevated IOP.

Dallas $^{42}$ showed a $2 \%$ incidence and Roper-Hall ${ }^{43}$ had an $8 \%$ incidence, but half of these cases were trauma related cataracts. Binkhorst Eye Group ${ }^{44}$ reported a $0 \%$ incidence of secondary glaucoma, as did Shepard ${ }^{45}$ and Pearce. ${ }^{46}$

A recent study reported $25 \%$ incidence of IOP spikes (>30 mmHg) 4-6h following uncomplicated phacoemulsification and IOL implantation. However, $24 \mathrm{~h}$ postoperatively, the incidence of IOP spikes declined significantly to $10 \%$ and in all cases IOP was within normal limits $(21 \mathrm{mmHg}) 3$ weeks later. ${ }^{47}$ Ahmed et $\mathrm{al}^{48}$ reported IOP greater than $28 \mathrm{mmHg}$ in $18 \%$ of nonglaucoma patients in the early $(3-7 \mathrm{~h}$ ) postoperative period, which decreased to below preoperative levels by 4 days in most individuals. ${ }^{48}$ The long-term risk of developing secondary glaucoma following a postoperative IOP spike therefore appears low.

Similar studies in patients undergoing either cataract extraction with IOL implantation or corneal transplantation (with or without cataract extraction) revealed a $22.5-32 \%$ incidence of transient postoperative IOP elevations ( $23 \mathrm{mmHg}$ ) but failed to identify any deleterious effects of these IOP spikes. ${ }^{49}$

\section{Effect of IOP spikes on visual fields}

Radius and Maumenee ${ }^{50}$ studied the effect of transient but significant elevations of IOP on visual fields. He presented clinical summaries of 24 patients who experienced IOP spikes up to $85 \mathrm{mmHg}$ lasting from $3 \mathrm{~h}$ to 5 days following angle closure glaucoma or cataract surgery. None of these subjects suffered permanent visual field defects after normal IOP was restored. These results are consistent with Duke-Elder ${ }^{51}$ statement that after one attack of high tension the visual field may be unaffected, although the author supports that repeated episodes result in general depression of all isopters. ${ }^{51}$

Sanborn et $a l^{52}$ using computerized static perimetry measured the visual fields during gravity inversion. They demonstrated that 11 of 19 eyes developed visual field defects, which recovered completely when subjects were retested in upright position several days later.

Visual field loss attributed to postoperative transient IOP rise has been described following pars plana vitrectomy and fluid-air exchange. Paques et $a l^{53}$ reported that $23 \%$ of the patients developed peripheral or relative arcuate field defect after vitrectomy for fullthickness macular holes. Yan et $a l^{54}$ documented visual field defects in $18 \%$ of the patients who underwent vitrectomy for macular hole, subretinal neovascular membrane, and epiretinal membrane proliferation. ${ }^{54}$ Ischaemia due to elevation or fluctuations in IOP was initially thought to be one of the causal factors of the field defects. ${ }^{55}$ Pendergast and McCuen II ${ }^{56}$ also suggested that ocular compression during face-down positioning might increase IOP and alter ophthalmic perfusion. ${ }^{56}$ However recent reports implicate mechanical or dehydration injury of the nerve fibre layer during cortical vitreous peeling or/and fluid-air exchange as the most likely mechanism of the visual field defects. ${ }^{57-59}$

In summary, the clinical data suggest that as a general rule, patients with normal eyes can tolerate a transient postoperative rise in IOP, with no detectable effect on visual function.

\section{IOP spikes in compromised optic disc}

For the already compromised optic disc with glaucomatous cupping or in patients prone to AION, including individuals with systemic arterial hypertension, diabetes mellitus, nocturnal hypotension, and anaemia, ${ }^{60,61}$ the same rise has been clearly demonstrated to have a deleterious effect on the remaining nerve fibres resulting in further visual field loss.

Kolker $^{62}$ reported that two of 23 eyes of patients with severe glaucomatous damage lost fixation following cataract extraction. The loss was attributed to postoperative elevation of IOP. Similarly, Savage et al ${ }^{63}$ found that $9.7 \%$ of patients with pre-existing advanced 
glaucoma developed progression of their visual field defects subsequent to cataract surgery. Moreover, it has been shown that glaucoma patients are more prone to exhibit IOP spikes postoperatively ${ }^{1}$ with almost half of them developing an IOP rise greater than $15 \mathrm{mmHg}$. Barak et $a l^{1}$ evaluated successive IOP changes for $24 \mathrm{~h}$ following cataract surgery, in glaucomatous and nonglaucomatous patients. The mean IOP in the glaucomatous group $(n=13)$ rose to $29.9 \mathrm{mmHg}$ at $8 \mathrm{~h}$ after surgery, with seven eyes showing an IOP greater than $35 \mathrm{mmHg}$. In the nonglaucomatous group $(\mathrm{n}=26)$ the mean IOP rose to $22.2 \mathrm{mmHg}$ at $12 \mathrm{~h}$. This additional risk factor for glaucomatous patients probably warrants prophylactic perioperative topical or systemic treatment.

Significant functional changes as a result of acute IOP elevation may also occur in eyes predisposed to AION. Hayreh $^{64}$ reported 13 cases in which AION developed immediately after an uncomplicated cataract extraction. He suggested that the almost invariable high rise of IOP during the immediate postoperative period plays a critical role in the production of postcataract extraction AION (PCE-AION) in eyes with vulnerable optic nerve head circulation. The IOP spikes result in reduction of the perfusion pressure (mean $\mathrm{BP}-\mathrm{IOP}$ ), which significantly compromises the blood supply to the optic disc. In addition, there is a high risk of PCE-AION development in the second eye of these patients, but this risk can be minimized with prophylactic measures. ${ }^{64}$

Based on the existing clinical data, it appears that IOP spikes in healthy eyes are probably harmless, but there is evidence to suggest that similar transient elevation of IOP may be detrimental in cases with compromised optic discs.

\section{Summary}

There is now a reasonable body of evidence to support the rigorous control of moderate IOP spikes in eyes that are particularly vulnerable to optic nerve damage. These eyes include those with advanced glaucomatous cupping and those predisposed to AION.

In healthy eyes, there is no compelling evidence to date that transient IOP spikes produce any significant permanent damage. It would therefore seem reasonable not to treat IOP spikes in normal eyes. Since the vast majority of IOP spikes occur in otherwise healthy eyes following uncomplicated cataract surgery, the authors suggest that it would be safe to leave these untreated. This would result in a significant saving of time and manpower as well as cost of medications, avoiding at the same time the potentially serious subclinical and clinical side effects of some IOP lowering agents. ${ }^{65}$

\section{References}

1 Barak A, Desatnik A, Ma-Naim T, Ashenkasi I, Neufeld A, Melamed S. Early postoperative intraocular pressure pattern in glaucomatous and nonglaucomatous patients. J Cataract Refract Surg 1996; 22: 607-611.

2 Podolsky MM, Ritch R. Elevated intraocular pressure in the immediate postoperative period after cataract extraction. Ann Ophthalmol 1981; 13: 1239-1240.

3 Galin MA, Lin LL, Obstbaum SA. Cataract extraction and intraocular pressure. Trans Ophthalmol Soc UK 1978; 98: 124.

4 Slomovic AR, Parrish II RK. Acute elevations of intraocular pressure following Nd:YAG laser posterior capsulotomy. Ophthalmology 1985; 92: 973-976.

5 Krupin T, Kolker AE, Kass MA, Becker B. Intraocular pressure the day of argon laser trabeculoplasty in primary open-angle glaucoma. Ophthalmology 1984; 91: 361-365.

6 Desai UR, Alhalel AA, Schiffman RM, Campen TJ, Sundar G, Muhich A. Intraocular pressure elevation after simple pars plana vitrectomy. Ophthalmology 1997; 104: 781-786.

7 Fog M. Om piaarteriens vasomotoriska reaktioner. Munksgaard: Copenhagen, 1934, p 183.

8 Porsaa K. Experimental studies on the vasomotor innervation of the retinal arteries. Acta Ophthal 1941; 18: 1-201.

9 Dollery CT, Henkind P, Kohner EM, Paterson JW. Effect of raised intraocular pressure on the retinal and choroidal circulation. Invest Ophthalmol 1968; 7: 191-197.

10 Alm A, Bill A. The oxygen supply to the retina II. Effects of high intraocular pressure and of increased arterial carbon dioxide tension on uveal and retinal blood flow in cats. Acta Physiol Scand 1972; 84: 306-319.

11 Alm A, Bill A. Ocular and optic nerve blood flow at normal and increased intraocular pressures in monkeys (Macaca irus): a study with radioactively labelled microspheres including flow determinations in brain and some other tissues. Exp Eye Res 1973; 15: 15-29.

12 Geijer C, Bill A. Effects of raised intraocular pressure on retinal, prelaminar, laminar, and retrolaminar optic nerve blood flow in monkeys. Invest ophthalmol Vis Sci 1979; 18: 1030-1042.

13 Sossi N, Anderson DR. Effect of elevated intraocular pressure on blood flow. Occurance in cat optic nerve head studied with Iodantipyrine I-125. Arch Ophthamol 1983; 101: 98-101.

14 Pillunat LE, Anderson DR, Knightom RW, Joos KM, Feuer WJ. Autoregulation of optic nerve head circulation in response to increased intraocular pressure. Exp Eye res 1997; 64: 737-744.

15 Joos KM, Kay MD, Pillunat LE, Harris A, Gendron EK, Feuer WJ et al. Effect of acute intraocular pressure changes on short posterior ciliary artery haemodynamics. $\mathrm{Br} \mathrm{J}$ Ophthalmol 1999; 83: 33-38.

16 Johnson EC, Deppmeier LMH, Wentzien SKF, Hsu I, Morrison JC. Chronology of optic nerve head and retinal responses to elevated intraocular pressure. Invest Ophthal Vis Sci 2000; 41: 431-442.

17 Gonzalez P, Epstein DL, Borras T. Gene upregulated in the human trabecular meshwork in response to elevated intraocular pressure. Invest Ophthal Vis Sci 2000; 41: 352-361.

18 Grehn F, Prost M. Function of retinal nerve fibers depends on perfusion pressure: neurophysiologic investigations during acute intraocular pressure elevation. Invest Ophthal Vis Sci 1983; 24: 347-353. 
19 Grehn F, Grusser O, Stange D. Effect of short-term intraocular pressure increase on cat retinal ganglion cell activity. Behav Brain Res 1984; 14: 109-121.

20 Alm A, Bill A. The oxygen supply to the retina I. Effects of changes in intraocular and arterial blood pressures, and in arterial $\mathrm{PO}_{2}$ and $\mathrm{PCO}_{2}$ on the oxygen tension in the vitreous body of the cat. Acta Physiol Scand 1972; 84: 261-274.

21 Hayreh SS, Revie IHS, Edwards J. Vasogenic origin of visual field defects and optic nerve changes in glacoma. $\mathrm{Br} J$ Ophthalmol 1970; 54: 461-472.

22 Ernest JT, Potts AM. Pathophysiology of the distal portion of the optic nerve. Am J Ophthalmol 1971; 72: 433-444.

23 Ernest JT. Autoregulation of optic-disk tension. Invest Ophthalmolo 1974; 13: 101-106.

24 Ernest JT. Optic disc blood flow. Trans Ophthalmol Soc UK 1976; 96: 348-351.

25 Weinstein JM, Funsch D, Page RB, Brennan B. Optic nerve blood flow and its regulation. Invest Ophthalmol Vis Sci 1982; 23: $640-645$

26 Weinstein JM, Duckrow RB, Beard D, Brennan KW. Regional optic nerve blood flow and autoregulation. Invest Ophthalmol Vis Sci 1983; 24: 1559-1565.

27 Grunwald JE, Riva CE, Stone RA, Keates EU, Petrig BL. Retinal autoregulation in open angle glaucoma. Ophthalmology 1986; 91: 1690-1694.

28 Riva CE, Grunwald JE, Petrig BL. Autoregulation of human retinal blood flow; an investigation with laser Doppler velocimetry. Invest Ophthalmol Vis Sci 1986; 27: 1706-1712.

29 Riva CE, Grunwald JE, Sinclair SH. Laser Doppler measurement of relative blood velocity in the human optic nerve head. Invest Ophthalmol Vis Sci 1982; 22: 241-248.

30 Best M, Toyofuku H. Ocular hemodynamics during induced ocular hypertension in man. Am J Ophthalmol 1974; 74: 932-939.

31 Anderson DR, Davis EB. Sensitivities of ocular tissues to acute pressure-induced ischaemia. Arch Ophthalmol 1975; 93 267-274.

32 Radius RL, Anderson DR. Breakdown of the normal optic nerve head blood-brain barrier following acute elevation of intraocular pressure in experimental animals. Invest Ophthalmol Vis Sci 1980; 19: 244-255.

33 Radius RL, Anderson DR. Reversibility of optic nerve damage inprimate eyes subjected to intraocular pressure above systolic blood pressure. Br J Ophthalmol 1981; 65: 661-672.

34 Li SH, Fu J Abler AS, Tso MOM, Lam TT. Apoptosis after transient elevated intraocular pressure. Invest Ophthalmol Vis Sci 1995; 36: S63 (305-213).

35 Hilding AC. Reduced ocular tension after cataract surgery. Arch Ophthalmol 1955; 53: 686-693.

36 Miller JE, Keskey GR, Becker B. Cataract extraction and aqueous outflow. Arch Ophthalmol 1957; 58: 401-406.

37 Galin MA, Baras I, Perry R. Intraocular pressure following cataract extraction. Arch Ophthalmol 1961; 66: 80-85.

38 Gormaz A. Ocular tension after cataract surgery. Am J Ophthalmol 1962; 53: 832-841.

39 Rich WJ, Radtke ND, Cohan BE. Early ocular hypertension after cataract extraction. Br J Ophthalmol 1974; 58: 725-731.

40 Rich WJ. Intraocular pressure and wound closure after cataract extraction. Trans Ophthal Soc UK 1968; 88: 437-439.
41 Smith JA, Anderson DR. Effect of the intraocular lens on intraocular pressure. Arch Ophthalmol 1976; 94: 1291-1294.

42 Dallas NL. Five year trial of the Binkhorst lens in aphakia. Trans Ophthalmol Soc UK 1970; 90: 725-732.

43 Roper-Hall MJ. Intraocular lenticuli. Br J Ophthalmol 1974 58: 715-717.

44 Binkhorst Eye Group, Zeeland, Netherlands. Read before the First International Course in Pseudophakia, Netherlands,1974.

45 Shepard DD. Intraocular lens. Read before the International Implant Society, Paris,1974.

46 Pearce JL. Long-term results of the Binkhorst iris clip lens in senile cataract. Br J Ophthalmol 1972; 56: 319-331.

47 Tranos P, Wickremasinghe S, Hildebrand D, Asaria R, Mearza A, Nouri S et al. Same vs first postoperative day review after uncomplicated phacoemulsification. Are we overtreating early intraocular pressure spikes? J Cataract Refract Surg 2003; 29(3): 508-512.

48 Ahmed IK, Kranemann C, Chipman M, Malam F. Revisiting early postoperative follow-up after phacoemulsification. J Cataract Refract Surg 2002; 28(1): 100-108.

49 Tuberville A, Tomoda T, Nissenkorn I, Wood TO. Postsurgical intraocular pressure elevation. I Am Intraocul Implant Soc 1983; 9: 309-312.

50 Radius RL, Maumenee AE. Visual field changes following acute elevation in intraocular pressure. Trans Am Acad Ophthalmol Otolaryngol 1977; 83: 61-68.

51 Duke-Elder S (ed). System of Ophthalmology, vol 11, Diseases of the lens and vitreous, Glaucoma and hypotony. CV Mosby Co.: St Louis, MO, 1969, p 602.

52 Sanborn GE, Friberg TR, Allen R. Optic nerve dysfunction during gravity inversion. Visual field abnormalities. Arch Ophthalmol 1987; 105: 774-776.

53 Paques M, Massin P, Santiago PY, Spielmann AC, Gaudric A. Visual loss after vitrectomy for full-thickness macular holes. Am J Ophthalmol 1997; 124: 88-94.

54 Yan H, Dhurjon L, Chow DR, Williams D, Chen JC. Visual field defect after pars plana vitrectomy. Ophthalmology 1998; 105: 1612-1616

55 Kerrison JB, Haller JA, Elman M, Miller NR. Visual field loss following vitreous surgery. Arch Ophthalmol 1996; 114: 564-569.

56 Pendergast SD, McCuen II BW. Visual field loss after macular hole surgery. Ophthalmology 1996; 103: 1069-1077.

57 Welch JC. Dehydration injury as a possible cause of visual field defect after pars plana vitrectomy for macular hole. Am J Ophthalmol 1997; 124: 698-699.

58 Hirata A, Yonemura N, Hasumura T, Murata Y, Negi A. Effect of infusion air pressure on visual field defects after macular hole surgery. Am J Ophthalmol 2000; 130: 611-616

59 Ezra E, Arden GB, Riordan-Eva P, Aylward GW, Gregor ZJ. Visual field loss following vitrectomy for stage 2 and 3 macular holes. Br J Ophthalmol 1996; 80: 519-525.

60 Buono LM, Foroozan R, Sergott RC, Savino PJ. Nonarteritic anterior ischemic optic neuropathy. Curr Opin Ophthalmol 2002; 13(6): 357-361.

61 Basile C, Addabbo G, Montanaro A. Anterior ischemic optic neuropathy and dialysis: role of hypotension and anemia. $J$ Nephrol 2001; 14(5): 420-423.

62 Kolker AE. Visual prognosis in advanced glaucoma: a comparison of medical and surgical therapy for retention of 
vision in 101 eyes with advanced glaucoma. Trans Am Ophthalmol Soc 1977; 75: 539-555.

63 Savage JA, Thomas JV, Belcher III CD, Simmons RJ. Extracapsular cataract extraction and posterior chamber intraocular lens implantation in glaucomatous eyes. Ophthalmology 1985; 92 : 1506-1516.
64 Hayreh SS. Anterior ischemic optic neuropathy. IV. Occurrence after cataract extraction. Arch Ophthalmol 1980; 98: 1410-1416.

65 Diggory P, Cassels-Brown A, Vail A, Abbey LM, Hillman JS. Avoiding unsuspected respiratory side-effects of topical timolol with cardioselective or sympathomimetic agents. Lancet 1995; 345: 1604-1606. 